Published in final edited form as:

Curr Opin Nephrol Hypertens. 2009 July ; 18(4): 298-302. doi:10.1097/MNH.0b013e32832c2264.

\title{
Parathyroid hormone signaling in bone and kidney
}

\author{
Minnkyong Lee and \\ Department of Physiology and Biophysics, University of Medicine and Dentistry of New Jersey- \\ Robert Wood Johnson Medical School, Piscataway, New Jersey 08854 \\ Nicola C. Partridge \\ Department of Physiology and Biophysics, University of Medicine and Dentistry of New Jersey- \\ Robert Wood Johnson Medical School, Piscataway, New Jersey 08854
}

\begin{abstract}
Purpose of review-Parathyroid hormone (PTH) maintains a physiological balance of calcium and phosphate concentrations by binding to its receptor on the plasma membrane of cells in bone and kidney. It signals through multiple pathways, including protein kinase A (PKA) and protein kinase $\mathrm{C}$ (PKC), although a preference for certain pathways is apparent in each organ and function. Here, we will review the recent advancements regarding PTH signaling in bone and kidney.
\end{abstract}

Recent findings-Wnt proteins have been reported as important regulators of bone metabolism in both PTH-dependent and independent pathways. Recent studies emphasize its role as a mediator of PTH signaling, since PTH treatment increased the expression of wnt 4 and sfrp 4 and decreased the expression of Wnt inhibitors such as Sost and sclerostin, leading to an increase in Wnt signaling. In kidney, sodium-hydrogen exchanger regulatory factor (NHERF) 1, originally known for its role in the retention of NaPi-IIa at the apical membrane, was shown to have multiple roles in PTH signaling, both as a mediator and regulator.

\section{Summary}

PTH activates a number of different signaling pathways by binding to a single receptor in bone and kidney. Recent studies demonstrate the involvement of novel factors, as well as additional roles for previously identified downstream-factors of PTH.

\section{Keywords}

Parathyroid hormone; PTH1R; PKA; PKC; NHERF1

Correspondence to Nicola C. Partridge, Dept. of Physiology and Biophysics, UMDNJ-Robert Wood Johnson Medical School, 683 Hoes Lane, Research Building 259, Piscataway, NJ 08854. Tel: 732-235-4552; Fax: 732-235-5038; partrinc@umdnj.edu.

Publisher's Disclaimer: This is a PDF file of an unedited manuscript that has been accepted for publication. As a service to our customers we are providing this early version of the manuscript. The manuscript will undergo copyediting, typesetting, and review of the resulting proof before it is published in its final citable form. Please note that during the production process errors may be discovered which could affect the content, and all legal disclaimers that apply to the journal pertain. 


\section{Introduction}

PTH plays a central role in calcium and phosphate homeostasis by targeting two main organs, bone and kidney. In kidney, it increases calcium reabsorption and inhibits phosphate reabsorption, and stimulates the conversion of 25-hydroxyvitamin $\mathrm{D}_{3}$ to 1,25 -

dihydroxyvitamin $\mathrm{D}_{3}$, which promotes intestinal calcium and phosphate absorption. In bone, PTH stimulates bone degradation, which leads to an increase in calcium and phosphate release. Produced by the chief cells of the parathyroid glands in response to low serum calcium concentration or high phosphate levels, PTH is cleaved to its biologically active form of 84-amino acids prior to secretion. Under normal conditions, binding to its receptor, PTH/PTHrP type1 receptor (PTH1R) [1, 2], activates multiple signaling pathways that collectively result in the restoration of serum calcium and phosphate levels.

\section{PTH signaling through PTH1R}

PTH1R is a seven transmembrane, G-protein coupled receptor linked to heterotrimeric Gproteins, Gs and Gq, implicated in the activation of adenylyl cyclase (AC)-PKA and phospholipase C (PLC)-PKC signaling pathways, respectively [2]. Calcium ion channels, such as transient receptor potential vanilloid 5 (TRPV5) in kidney [3, 4*], and other pathways, including phospholipase D and extracellular signal-regulated kinases (ERK)/ mitogen-activated protein kinases (MAPK) [5, 6], have been shown to be activated as well. In humans and rodents, PTH predominantly functions through PTH1R found on the surface of osteoblasts and stromal cells in bone and of kidney cells on the apical and basolateral membranes of tubules $[1,2,7,8]$, although additional receptors have been identified in other species and tissues $[9,10]$. Different PTH peptide fragments that stimulate only certain pathways have been useful in dissecting the separate signaling pathways that mediate PTH signaling. The synthetic peptide PTH (1-34) has the same biological effect as the full-length endogenous PTH protein (1-84), whereas PTH (1-31) only activates PKA pathways, and PTH (3-34) only activates PKC pathways [11]. Binding of residues 1 and 2 of PTH (1-34) occurs in the third extracellular loop of PTH1R [12]. Residues 1-9 are critical for receptor activation through interaction with the transmembrane region of the receptor [13], while binding affinity is primarily determined by association of residues 15-34 and the aminoterminal extracellular domain of PTH1R [14].

Termination of PTH1R signaling is achieved through negative feedback of PTH secretion in response to restoration of calcium levels, or by a desensitization-internalization process of the receptor that requires GPCR kinase-2 (GRK2). Phosphorylation of PTH1R at its carboxy-terminal tail by GRK2 occurs promptly after PTH binding, which initiates desensitization of the receptor, ultimately leading to receptor internalization and termination of the signal [15]. Substituting PTH1R with a phosphorylation-deficient receptor has been shown to impair internalization and prolong cAMP generation [16]. PTH signaling is also regulated by PTH-regulated proteins, such as osteopontin, which suppresses PTH signaling in osteoblasts [17], and PTH1R expression is down-regulated by PTH itself as well $[18,19]$. In addition, PTH1R is able to bind NHERF1, a cytoplasmic scaffolding protein, which confers added levels of regulation. Through direct interaction, NHERF1 promotes PTH1R 
relocation to regions in the plasma membrane that are closer to cytoskeletal fibers [20], as well as inhibition of PTH1R down-regulation [21**].

\section{PTH signaling in bone}

Bone undergoes constant remodeling in response to endocrine and paracrine signals, and is maintained through a delicate balance between bone formation and degradation. Bone resorption leads to the release of calcium and phosphate ions as a result of the degradation of hydroxyapitite, a main mineral component of bone matrix. PTH has a dichotomous role regarding bone metabolism; continuous infusion causes a catabolic response resulting in bone loss, whereas intermittent injection leads to an anabolic response characterized by increased bone mineral density (BMD). The classic role of PTH as a catabolic agent has been well-studied; however the mechanism underlying its anabolic role remains to be understood. PTH primarily utilizes the PKA pathway in exerting both its catabolic and anabolic effects [19, 22, 23*]. PKC activation by PTH has been associated with the activation of L-type voltage-gated calcium channels [24] or ERK/MAPK pathways [5]. However, activation of PKC and intracellular calcium signaling pathways seems to play a limited role in PTH signaling in bone, especially in its anabolic responses [19], thus it is likely that the dual effects of PTH arise from the divergent pathways it activates.

Upon binding to its receptor, PTH signals a shift in gene expression patterns in osteoblasts, which normally function as bone-forming cells, to participate in the bone-resorption process by secreting various cytokines and bone-degrading proteases. Among these factors, several are involved in regulating osteoclast differentiation and activation. Two such crucial molecules are macrophage colony-stimulating factor and receptor activator of nuclear factor kappa B ligand (RANKL). The expression of RANKL is increased by PTH mainly through the PKA pathway in osteoblasts and bone marrow cultures [25] as well as in vivo [19]. The cytokines, monocyte chemoattractant protein-1 (MCP-1) and interleukin-18 (IL-18) [26*], are also molecules synthesized by osteoblasts upon PTH treatment that target and control osteoclasts. Both molecules are regulated via the PKA signaling pathway in vitro and in vivo. MCP-1 induces osteoclastogenesis, especially by enhancing fusion [27, 28], and IL-18 inhibits osteoclast formation [29]. Thus, through its action on osteoblasts, PTH is able to regulate the bone microenvironment both directly and indirectly. It appears that the anabolic protocol regulates the cytokines transiently, while the catabolic protocol causes their constant expression leading to prolonged activation of osteoclasts.

Many transcription factors are regulated through the PKA pathway with PTH stimulation, contributing to the change in gene expression in osteoblasts described before. Members of the ATF/CREB family of leucine zipper transcription factors which bind to cAMP response elements (CRE) are among those factors activated by PTH through PKA. In addition to the well-studied phosphorylation of CREB via PKA [30-32], PTH-stimulation of activating transcription factor 4 (ATF4) transcriptional activity is also PKA-dependent [23*]. Promoter analysis of PTH-regulated genes identified ATF4 as a transcription factor that plays a role in

PTH-signal transduction in osteoblastic cells, and its own expression was also increased with PTH treatment $\left[23^{*}, 33\right]$. Another member of the ATF/CREB family, CRE modulator (CREM), has been shown to be implicated in PTH signaling, where mice lacking CREM 
responded with increased osteoclastogenesis in a catabolic manner to PTH intermittent injections, rather than having the typical anabolic response [34]. In the microarray analyses performed in our laboratory, CREM expression was also shown to be regulated by PTH, with a 20-fold increase after intermittent administration of PTH [19]. Thus, it is likely that CREM is stimulated by PTH as a negative regulator of osteoclast formation in inducing the anabolic response. The expression and activity of Runx2, an osteoblast-specific transcription factor essential for osteogenesis, is also augmented by PTH [35, 36]. Phosphorylation of Runx2 increases with PTH treatment in osteoblastic cells by a PKA-dependent pathway [36], and allows it to function as a transcriptional activator of certain genes upregulated by PTH, such as matrix metalloproteinase 13 and Bcl-2, an anti-apoptotic gene [37]. This increase of Bcl-2 contributes to the anabolic response to PTH, most likely by increasing osteoblast number by enhancing survival signaling, leading to increased bone formation.

Recently, Wnt proteins have become acknowledged as important regulators of bone metabolism in both PTH-dependent and independent responses [38**, 39]. Wnt proteins, classically known for their essential role in developmental processes, are secreted glycoproteins that bind to their receptors, one of ten Frizzled molecules, found in a variety of tissues. Canonical Wnt signaling involves a receptor complex composed of one Frizzled receptor and LDL receptor-related protein (LRP) 5 or 6 , which leads to the activation of $\beta$ catenin and subsequent regulation of gene expression. Microarray analyses of femoral RNA from rats treated with either intermittent or continuous PTH show that the expression of genes encoding proteins implicated in Wnt signaling pathways, including wnt 4 and sfrp4 (secreted frizzled related protein 4), an antagonist of Wnt signaling, are up-regulated by both treatment conditions [19]. However, Wnt4 seems to signal through non-canonical pathways in mature osteoblasts [40]. PTH regulation of Wnt signaling in bone was further demonstrated by a recent study which used transgenic mice expressing a constitutively active PTH receptor exclusively in osteocytes [38**]. These mice, which display increased BMD and bone remodeling, had increased Wnt signaling due to decreased expression of Wnt antagonists Sost and sclerostin. Furthermore, deletion of LRP5 in these mice led to the loss of the increased BMD phenotype, indicating a role for LRP5 in PTH-regulated Wnt signaling. In another study, LRP6 was shown to be involved in PTH signaling in osteoblasts by forming a complex with PTH1R [41]. These data suggest a role for canonical Wnt signaling in mediating PTH signaling in bone.

\section{PTH signaling in kidney}

The kidney is the primary organ that regulates ion homeostasis across the whole body by carefully coupling the excretion and reabsorption of ions. In kidney, PTH stimulates calcium reabsorption in the distal tubule by activating specific ion channels, such as TRPV5 [3, 4*], and increases phosphate excretion in the proximal tubule mainly by regulating sodiumcoupled cotransporters via both PKA and PKC-dependent pathways. It also enhances intestinal calcium and phosphate uptake by stimulating the conversion of 25-hydroxyvitamin $\mathrm{D}_{3}$ to 1,25 -dihydroxyvitamin $\mathrm{D}_{3}$, the biologically most potent form, by transcriptional activation of 25-hydroxyvitamin D 1a hydroxylase [42]. 
Phosphate reabsorption across the apical membrane of renal proximal tubules mainly occurs through two sodium-dependent phosphate cotransporters, NaPi-IIa and NaPi-IIc, that are exclusively expressed in the brush border membrane (BBM) of the proximal tubules [43]. PTH binding to its receptors at either membrane, apical or basolateral, results in the downregulation of $\mathrm{NaPi}$-IIa and $\mathrm{NaPi}-\mathrm{IIc}$ in which the transporter is removed from the BBM via clathrin-coated pits $[44,45]$. The two signals are initiated through different pathways; activation of apical receptors leads to PLC-PKC stimulation, whereas basolateral receptors utilize the PKA pathway [46]. While it was previously proposed that the two pathways eventually converge downstream to activate ERK/MAPK [47], a recent study by the same team suggests otherwise that in fact, ERK/MAPK most likely plays an insignificant role in PTH-induced inhibition of phosphate reabsorption [48]. Following endocytosis, NaPi-IIa is eventually transported to the lysosome for degradation [44]. Both PTH1R and NaPi-IIa have a postsynaptic density 95/disc-large/zona occludens (PDZ)-binding motif, which allows them to interact directly with PDZ-containing proteins, including NHERFs [49]. Such proteins with PDZ domains are able to act as a scaffold between PTH1R and NaPi-IIa, and mediate PTH-signaling.

NHERF1, expressed in multiple tissues, including bone and kidney, has two PDZ domains and a merlin-ezrin-radixin-moesin (MERM) binding domain. Originally identified as a regulator of sodium-hydrogen exchanger type 3 , it has been shown to bind to other proteins that contain PDZ-binding motifs, including PTH1R [50]. The MERM domain is involved with interacting with the cytoskeleton as it mediates binding with proteins such as Ezrin, an actin-associated protein. NHERF1 colocalizes with NaPi-IIa, and forms a complex through its PDZ domain [49], stabilizing the expression of NaPi-IIa at the apical membrane via its MERM domain. PTH treatment disrupts this complex by stimulating the phosphorylation of NHERF1, which leads to the dissociation and subsequent endocytosis of NaPi-IIa [51, 52]. PTH-regulation of NaPi-IIa internalization and interaction with NHERF1 is most likely mediated by the PLC-PKC pathway, as NHERF1 is able to bind PLC isoforms [53], and decoupling of PTH1R to PLC was observed in NHERF1-deficient mice [54]. In patients with abnormal renal phosphate reabsorption, NHERF1 mutations were identified, and in kidney cells transfected with mutant NHERF1, cAMP generation and inhibition of phosphate uptake was increased with PTH treatment [55**]. This suggests an regulatory role for NHERF1 in downstream signaling of PTH, which is similar to that previously observed, in which expression of NHERF1 reduces PTH-induced cAMP generation, whereas the absence of NHERF1 increases the cAMP response in cultured cells [50]. These data suggest that NHERF1 functions as a mediator of PTH-regulation of renal phosphate reabsorption, as well as an inhibitor of the PTH-activated PKA pathway. Most recently, it was shown that induction of NHERF1 expression in rat osteosarcoma cells inhibited PTH1R desensitization by blocking dissociation of PTH1R from Ga proteins [21**], thereby acting as a positive regulator of PTH1R. Thus, it appears that apart from its role in regulating NaPi-IIa expression at the BBM, NHERF1 is also involved in PTH-signaling at many levels in different tissues

Calcium reabsorption primarily takes place in the distal tubules and connecting tubules [56]. From the tubular lumen, calcium ions cross the apical membrane via TRPV5, a highly selective calcium channel, and are then transported across the basolateral membrane into the 
blood system by the sodium/calcium-exchanger 1 (NCX1) and the plasma membrane ATPase [57]. Compared to control rats, parathyroidectomized rats had lower expression levels of renal calcium transport proteins, such as TRPV5 and NCX1, and displayed hypocalcemia due to reduced calcium reabsorption [3]. TRPV5 is regulated through the PKC-signaling pathway by extracellular calcium-sensing receptors [58]. PTH regulation of TRPV5 also occurs through PKC as it was recently shown that PTH-dependent increase in TRPV 5 current density in cultured cells was prevented by PKC inhibitors [4*]. In kidney, PTH regulates calcium reabsorption at both transcriptional and post-translational levels by regulating the expression of calcium transport proteins as well as their activity, yet PTHregulation of the promoter of related genes such as TRPV5 has not been reported.

\section{Conclusion}

PTH is able to activate multiple signaling pathways in cells that express PTH1R and even those that do not via indirect regulation in a paracrine manner; however as the work summarized here indicates, there are preferences for different pathways depending on cell type and function. In bone, the AC-PKA pathway is the primary pathway utilized by PTH, particularly in its anabolic responses. In kidney, both PKA and PKC pathways are activated by PTH in the proximal tubules for regulation of phosphate reuptake, whereas calcium reabsorption in the distal tubules seems to be mainly regulated through PKC. Recent studies suggesting the implication of Wnt-signaling and multiple roles of NHERF1 downstream of PTH are very interesting, however they remain to be further investigated.

\section{Acknowledgements}

This work was supported by National Institutes of Health Grant DK47420 (to N.C.P.).

\section{References and recommended reading}

[1]. Juppner H, Abou-Samra AB, Freeman M et al. A G protein-linked receptor for parathyroid hormone and parathyroid hormone-related peptide. Science 1991; 254:1024-6. [PubMed: 1658941]

[2]. Abou-Samra AB, Juppner H, Force T et al. Expression cloning of a common receptor for parathyroid hormone and parathyroid hormone-related peptide from rat osteoblast-like cells: a single receptor stimulates intracellular accumulation of both cAMP and inositol trisphosphates and increases intracellular free calcium. Proc Natl Acad Sci U S A 1992; 89:2732-6. [PubMed: 1313566]

[3]. van Abel M, Hoenderop JG, van der Kemp AW et al. Coordinated control of renal Ca(2+) transport proteins by parathyroid hormone. Kidney Int 2005; 68:1708-21. [PubMed: 16164647]

*[4]. Cha SK, Wu T, Huang CL. Protein kinase C inhibits caveolae-mediated endocytosis of TRPV5. Am J Physiol Renal Physiol 2008; 294:F1212-21. [PubMed: 18305097] This study suggests that PTH regulation of TRPV5 activity is mediated through PKC-dependent pathways.

[5]. Swarthout JT, Doggett TA, Lemker JL, Partridge NC. Stimulation of extracellular signal-regulated kinases and proliferation in rat osteoblastic cells by parathyroid hormone is protein kinase Cdependent. J Biol Chem 2001; 276:7586-92. [PubMed: 11108712]

[6]. Wang B, Yang Y, Friedman PA. Na/H exchange regulatory factor 1, a novel AKT-associating protein, regulates extracellular signal-regulated kinase signaling through a B-Raf-mediated pathway. Mol Biol Cell 2008; 19:1637-45. [PubMed: 18272783]

[7]. Lee K, Brown D, Urena P et al. Localization of parathyroid hormone/parathyroid hormone-related peptide receptor mRNA in kidney. Am J Physiol 1996; 270:F186-91. [PubMed: 8769838] 
[8]. Yang T, Hassan S, Huang YG et al. Expression of PTHrP, PTH/PTHrP receptor, and Ca(2+)sensing receptor mRNAs along the rat nephron. Am J Physiol 1997; 272:F751-8. [PubMed: 9227636]

[9]. Rubin DA, Juppner H. Zebrafish express the common parathyroid hormone/parathyroid hormonerelated peptide receptor (PTH1R) and a novel receptor (PTH3R) that is preferentially activated by mammalian and fugufish parathyroid hormone-related peptide. J Biol Chem 1999; 274:2818590. [PubMed: 10497171]

[10]. Usdin TB, Gruber C, Bonner TI. Identification and functional expression of a receptor selectively recognizing parathyroid hormone, the PTH2 receptor. J Biol Chem 1995; 270:15455-8. [PubMed: 7797535]

[11]. Jouishomme H, Whitfield JF, Gagnon L et al. Further definition of the protein kinase C activation domain of the parathyroid hormone. J Bone Miner Res 1994; 9:943-9. [PubMed: 8079668]

[12]. Lee C, Luck MD, Juppner H et al. Homolog-scanning mutagenesis of the parathyroid hormone (PTH) receptor reveals PTH-(1-34) binding determinants in the third extracellular loop. Mol Endocrinol 1995; 9:1269-78. [PubMed: 8544835]

[13]. Shimizu M, Potts JT, Jr., Gardella TJ. Minimization of parathyroid hormone. Novel aminoterminal parathyroid hormone fragments with enhanced potency in activating the type-1 parathyroid hormone receptor. J Biol Chem 2000; 275:21836-43. [PubMed: 10777513]

[14]. Gardella TJ, Wilson AK, Keutmann HT et al. Analysis of parathyroid hormone's principal receptor-binding region by site-directed mutagenesis and analog design. Endocrinology 1993; 132:2024-30. [PubMed: 8386605]

[15]. Tawfeek HA, Qian F, Abou-Samra AB. Phosphorylation of the receptor for PTH and PTHrP is required for internalization and regulates receptor signaling. Mol Endocrinol 2002; 16:1-13. [PubMed: 11773434]

[16]. Miedlich SU, Abou-Samra AB. Eliminating phosphorylation sites of the parathyroid hormone receptor type 1 differentially affects stimulation of phospholipase $\mathrm{C}$ and receptor internalization. Am J Physiol Endocrinol Metab 2008; 295:E665-71. [PubMed: 18577695]

[17]. Ono N, Nakashima K, Rittling SR et al. Osteopontin negatively regulates parathyroid hormone receptor signaling in osteoblasts. J Biol Chem 2008; 283:19400-9. [PubMed: 18417476]

[18]. Gonzalez EA, Martin KJ. Coordinate regulation of PTH/PTHrP receptors by PTH and calcitriol in UMR 106-01 osteoblast-like cells. Kidney Int 1996; 50:63-70. [PubMed: 8807573]

[19]. Li X, Liu H, Qin L et al. Determination of dual effects of parathyroid hormone on skeletal gene expression in vivo by microarray and network analysis. J Biol Chem 2007; 282:33086-97. [PubMed: 17690103]

[20]. Wheeler D, Garrido JL, Bisello A et al. Regulation of parathyroid hormone type 1 receptor dynamics, traffic, and signaling by the $\mathrm{Na}+/ \mathrm{H}+$ exchanger regulatory factor -1 in rat osteosarcoma ROS 17/2.8 cells. Mol Endocrinol 2008; 22:1163-70. [PubMed: 18202147]

**[21]. Wang B, Yang Y, Abou-Samra A, Friedman P. NHERF1 regulates parathyroid hormone receptor desensitization: interference with \{beta\}-arrestin Binding. Mol Pharmacol 2009.The results here suggest a mechanism for NHERF1 regulation of PTH1R desensitization and subsequent internalization.

[22]. Yang D, Singh R, Divieti P et al. Contributions of parathyroid hormone (PTH)/PTH-related peptide receptor signaling pathways to the anabolic effect of PTH on bone. Bone 2007; 40:145361. [PubMed: 17376756]

*[23]. Yu S, Franceschi RT, Luo M et al. Parathyroid hormone increases activating transcription factor 4 expression and activity in osteoblasts: requirement for osteocalcin gene expression. Endocrinology 2008; 149:1960-8. [PubMed: 18187540] Regulation of ATF4 by PTH is mainly mediated through PKA.

[24]. Fritsch J, Chesnoy-Marchais D. Dual modulation of the L-type calcium current of rat osteoblastic cells by parathyroid hormone: opposite effects of protein kinase $\mathrm{C}$ and cyclic nucleotides. Cell Signal 1994; 6:645-55. [PubMed: 7857768]

[25]. Lee SK, Lorenzo JA. Regulation of receptor activator of nuclear factor-kappa B ligand and osteoprotegerin mRNA expression by parathyroid hormone is predominantly mediated by the 
protein kinase a pathway in murine bone marrow cultures. Bone 2002; 31:252-9. [PubMed: 12110442]

*[26]. Raggatt LJ, Qin L, Tamasi J et al. Interleukin-18 is regulated by parathyroid hormone and is required for its bone anabolic actions. J Biol Chem 2008; 283:6790-8. [PubMed: 18165223] Studies using mice lacking IL-18 demonstrate a role for IL-18 in the anabolic actions of PTH in bone.

[27]. Li X, Qin L, Bergenstock M et al. Parathyroid hormone stimulates osteoblastic expression of MCP-1 to recruit and increase the fusion of pre/osteoclasts. J Biol Chem 2007; 282:33098-106. [PubMed: 17690108]

[28]. Kim MS, Day CJ, Morrison NA. MCP-1 is induced by receptor activator of nuclear factor$\{$ kappa\}B ligand, promotes human osteoclast fusion, and rescues granulocyte macrophage colony-stimulating factor suppression of osteoclast formation. J Biol Chem 2005; 280:16163-9. [PubMed: 15722361]

[29]. Horwood NJ, Udagawa N, Elliott J et al. Interleukin 18 inhibits osteoclast formation via T cell production of granulocyte macrophage colony-stimulating factor. J Clin Invest 1998; 101:595603. [PubMed: 9449693]

[30]. Swarthout JT, Tyson DR, Jefcoat SC, Jr., Partridge NC. Induction of transcriptional activity of the cyclic adenosine monophosphate response element binding protein by parathyroid hormone and epidermal growth factor in osteoblastic cells. J Bone Miner Res 2002; 17:1401-7. [PubMed: 12162494]

[31]. Fu Q, Jilka RL, Manolagas SC, O’Brien CA. Parathyroid hormone stimulates receptor activator of NFkappa B ligand and inhibits osteoprotegerin expression via protein kinase A activation of cAMP-response element-binding protein. J Biol Chem 2002; 277:48868-75. [PubMed: 12364326]

[32]. Hinoi E, Ueshima T, Hojo $\mathrm{H}$ et al. Up-regulation of per mRNA expression by parathyroid hormone through a protein kinase A-CREB-dependent mechanism in chondrocytes. J Biol Chem 2006; 281:23632-42. [PubMed: 16777848]

[33]. Qin L, Qiu P, Wang L et al. Gene expression profiles and transcription factors involved in parathyroid hormone signaling in osteoblasts revealed by microarray and bioinformatics. J Biol Chem 2003; 278:19723-31. [PubMed: 12644456]

[34]. Liu F, Lee SK, Adams DJ et al. CREM deficiency in mice alters the response of bone to intermittent parathyroid hormone treatment. Bone 2007; 40:1135-43. [PubMed: 17275432]

[35]. Krishnan V, Moore TL, Ma YL et al. Parathyroid hormone bone anabolic action requires Cbfa1/ Runx2-dependent signaling. Mol Endocrinol 2003; 17:423-35. [PubMed: 12554794]

[36]. Selvamurugan N, Shimizu E, Lee M et al. Identification and characterization of Runx2 phosphorylation sites involved in matrix metalloproteinase-13 promoter activation. FEBS Lett 2009.

[37]. Bellido T, Ali AA, Plotkin LI et al. Proteasomal degradation of Runx 2 shortens parathyroid hormone-induced anti-apoptotic signaling in osteoblasts. A putative explanation for why intermittent administration is needed for bone anabolism. J Biol Chem 2003; 278:50259-72. [PubMed: 14523023]

**[38]. O'Brien CA, Plotkin LI, Galli C et al. Control of bone mass and remodeling by PTH receptor signaling in osteocytes. PLoS ONE 2008; 3:e2942. [PubMed: 18698360] This study demonstrates the regulation of Wnt signaling by PTH in osteocytes in both LRP5-dependent and independent pathways.

[39]. Pederson L, Ruan M, Westendorf JJ et al. Regulation of bone formation by osteoclasts involves Wnt/BMP signaling and the chemokine sphingosine-1-phosphate. Proc Natl Acad Sci U S A 2008; 105:20764-9. [PubMed: 19075223]

[40]. Bergenstock MK, Partridge NC. Parathyroid hormone stimulation of noncanonical Wnt signaling in bone. Ann N Y Acad Sci 2007; 1116:354-9. [PubMed: 18083937]

[41]. Wan M, Yang C, Li J et al. Parathyroid hormone signaling through low-density lipoproteinrelated protein 6. Genes Dev 2008; 22:2968-79. [PubMed: 18981475] 
[42]. Brenza HL, Kimmel-Jehan C, Jehan F et al. Parathyroid hormone activation of the 25hydroxyvitamin D3-1alpha-hydroxylase gene promoter. Proc Natl Acad Sci U S A 1998; 95:1387-91. [PubMed: 9465024]

[43]. Custer M, Lotscher M, Biber J et al. Expression of Na-P(i) cotransport in rat kidney: localization by RT-PCR and immunohistochemistry. Am J Physiol 1994; 266:F767-74. [PubMed: 7515582]

[44]. Bacic D, Lehir M, Biber J et al. The renal Na+/phosphate cotransporter NaPi-IIa is internalized via the receptor-mediated endocytic route in response to parathyroid hormone. Kidney Int 2006; 69:495-503. [PubMed: 16514432]

[45]. Segawa H, Yamanaka S, Onitsuka A et al. Parathyroid hormone-dependent endocytosis of renal type IIc Na-Pi cotransporter. Am J Physiol Renal Physiol 2007; 292:F395-403. [PubMed: 16985216]

[46]. Traebert M, Volk1 H, Biber J et al. Luminal and contraluminal action of 1-34 and 3-34 PTH peptides on renal type IIa Na-P(i) cotransporter. Am J Physiol Renal Physiol 2000; 278:F792-8. [PubMed: 10807591]

[47]. Bacic D, Schulz N, Biber J et al. Involvement of the MAPK-kinase pathway in the PTH-mediated regulation of the proximal tubule type IIa $\mathrm{Na}+\mathrm{Pi}$ cotransporter in mouse kidney. Pflugers Arch 2003; 446:52-60. [PubMed: 12690463]

[48]. Cunningham R, Biswas R, Brazie M et al. Signaling pathways utilized by PTH and dopamine to inhibit phosphate transport in mouse renal proximal tubule cells. Am J Physiol Renal Physiol 2009; 296:F355-61. [PubMed: 18987113]

[49]. Gisler SM, Stagljar I, Traebert M et al. Interaction of the type IIa Na/Pi cotransporter with PDZ proteins. J Biol Chem 2001; 276:9206-13. [PubMed: 11099500]

[50]. Mahon MJ, Donowitz M, Yun CC, Segre GV. Na(+)/H(+ ) exchanger regulatory factor 2 directs parathyroid hormone 1 receptor signalling. Nature 2002; 417:858-61. [PubMed: 12075354]

[51]. Deliot N, Hernando N, Horst-Liu Z et al. Parathyroid hormone treatment induces dissociation of type IIa Na+-P(i) cotransporter-Na+/H+ exchanger regulatory factor-1 complexes. Am J Physiol Cell Physiol 2005; 289:C159-67. [PubMed: 15788483]

[52]. Weinman EJ, Biswas RS, Peng G et al. Parathyroid hormone inhibits renal phosphate transport by phosphorylation of serine 77 of sodium-hydrogen exchanger regulatory factor-1. J Clin Invest 2007; 117:3412-20. [PubMed: 17975671]

[53]. Tang Y, Tang J, Chen Z et al. Association of mammalian trp4 and phospholipase C isozymes with a PDZ domain-containing protein, NHERF. J Biol Chem 2000; 275:37559-64. [PubMed: 10980202]

[54]. Capuano P, Bacic D, Roos M et al. Defective coupling of apical PTH receptors to phospholipase $\mathrm{C}$ prevents internalization of the Na+-phosphate cotransporter NaPi-IIa in Nherf1-deficient mice. Am J Physiol Cell Physiol 2007; 292:C927-34. [PubMed: 16987995]

**[55]. Karim Z, Gerard B, Bakouh N et al. NHERF1 mutations and responsiveness of renal parathyroid hormone. N Engl J Med 2008; 359:1128-35. [PubMed: 18784102] NHERF1 mutations identified in patients with diminished renal phosphate reuptake capacity, yet normal serum PTH levels, suggest a role for NHERF1 downstream of PTH signaling.

[56]. Guyton AC, Hall JE. Textbook of medical physiology Philadelphia: Elsevier Saunders; 2006 xxxv, 1116 p. p.

[57]. Lambers TT, Bindels RJ, Hoenderop JG. Coordinated control of renal Ca2+ handling. Kidney Int 2006; 69:650-4. [PubMed: 16518325]

[58]. Topala CN, Schoeber JP, Searchfield LE et al. Activation of the $\mathrm{Ca}(2+)$-sensing receptor stimulates the activity of the epithelial $\mathrm{Ca}(2+)$ channel TRPV5. Cell Calcium 2009. 